\title{
GRACE, the Chandler Wobble and Interpretations of Terrestrial Water Transient Storage
}

\author{
Reginald R. Muskett \\ Geophysical Institute, University of Alaska Fairbanks, Fairbanks, USA \\ Email: reginald.muskett@gmail.com
}

How to cite this paper: Muskett, R.R. (2021) GRACE, the Chandler Wobble and Interpretations of Terrestrial Water Transient Storage. International Journal of Geosciences, 12, 102-120.

https://doi.org/10.4236/ijg.2021.122007

Received: January 5, 2021

Accepted: February 19, 2021

Published: February 22, 2021

Copyright $\odot 2021$ by author(s) and Scientific Research Publishing Inc. This work is licensed under the Creative Commons Attribution International License (CC BY 4.0).

http://creativecommons.org/licenses/by/4.0/

\section{(c) (i) Open Access}

\begin{abstract}
Measuring Terrestrial Water Transient Storage in its various components of Earth by orbiting sensors on satellites has been a quest for more than 40 years. Not only in the Hydrology community but also Climatology and Meteorology, Geology, Geodesy, Geophysics and Oceanography have the challenge to attempt to first learn how to measure, then measure and assess the results. The importance is that Earth's environments are changing and human communities, local and national governing bodies need ability to assess current hazards and to have predictive capabilities for society both local and international. So too the Gravity Recovery and Climate Experiment (GRACE) has joined the ongoing international space-based missions. There will be more after GRACE. For now is an important juncture in the effort to measure Terrestrial Water Transient Storage to ask, "What can GRACE measure and what is GRACE measuring"? Results of this investigation of the GRACE datasets by spectral methods indicate the detection of the Chandler Wobble but the Annual Wobble is aliased and below significance. Therefore, interpretations of Terrestrial Water Transient Storage are failed.
\end{abstract}

\section{Keywords}

Polar Motion, Chandler Wobble, Annual Wobble, GRACE, Geophysical Geodesy

\section{Introduction}

To gain a predictive understanding of water in Earth's changing environments, atmosphere-geology-hydrology and potential hazards to human communities, infrastructures and sustainable living, our ability to measure terrestrial water transient storage (a.k.a. changes of terrestrial water storage) must evolve. Earth 
environment monitoring by satellite began with the NASA Earth Resources Technology Satellite launched in 1972 and lead to the joint NASA-USGS Landsat Program [1] [2]. Notions of terrestrial water transient storage, a component of the Earth's energy and mass balance have been at the core of NASA's Decadal Survey Global Cycles of Energy and Water and other governmental agencies both national and international starting with NASA's Mission To Planet Earth (1989) for more than two decades [3] [4]. These notions have driven the development of Electromagnetic-Optical sensors and satellites missions in attempts to measure and assess potential feedbacks, human and natural, in global and regional meteorology and climatology of Earth. In particular feedbacks, which may be caused by human activities and potential run-away changes (amplification or reduction) of natural cycles have become the interest of many national and international activist and governance organizations [5]-[11].

Our knowledge of climatology, the causes and workings of Earth's past, present and possible future "climate" come directly from empirical observations of the Earth's rocks, those exposed on the continents and islands and cores recovered from land and in the depths of ocean basins, i.e. Geology, spaning a history of $4.5 \mathrm{Ga}$. Examples include the Geological Sea Level curves, the Phanerozoic Eon atmosphere $\mathrm{CO}_{2}$ concentration, trangression and regressions on the continents and inferred surface continental temperature curves and the empirical linkage of the $405 \mathrm{Ky}$ Malankovitch to radiometric-magnetostratigraphy of the last 215 million years of Earth history [12]-[21]. In these renderings, $\mathrm{CO}_{2}$ concentration, sea level and land temperature are proxy-parameters that may be associated to "inferred climate" during the Eras of Earth's history.

With the advent of satellite technologies and sensor-systems in near-Earth orbit, and the growth of electronic computational methods and techniques, attempt to measure meteorological parameters and possibly "climate parameters" has been a growing enterprise fraught with many failures and miss-interpretations. The emphasis from the ideas of the 1950s was to use numerical machine codes, i.e. computer models, to ingest meteorological measurements and over a sufficiently long period of time, "climate" would emerge from the model output, i.e. both the match of current "climate" and a prediction of future "climate". This leads to the creation of the United Nations sponsored World Meteorological Office, International Panel on Climate Change and the Framework Convention on Climate Change. The term "Climate Change" and physical "climate" parameters are to this day still undefined (i.e. undiscovered), though meteorological parameters are assumed by necessity. Of note, the "satellite era" measurements currently cover less than 1 millionth of Earth's history.

In the 1980s various ideas were moving among researchers in academia and government agencies about employing gravity sensors, i.e. gravimeters, and magnetometers to measure any changes of the Earth's gravity and magnetic fields from near-Earth orbit, using knowledge from exploration geophysics methods and techniques. Germany and the United States developed several missions. The 
space agencies of both countries partnered in the mid-1990s to develop such a joint mission to measure the time-variable gravity field from near-Earth orbit. This became the Gravity Recovery and Climate Experiment (GRACE) program of Germany's DLR and U.S.A.'s NASA. In both countries several universities and other national agencies partnered as well as those from France and Italy. GRACE was launched in March 2002 (end-of-mission March 2018) and GRACE Follow-On was launched in May 2018.

This report gives details of: 1) A critical flaw in the GRACE and GRACE Follow-On mission design; 2) The affect of the flaw on derived global datasets regarding Terrestrial Water Transient Storage interpretations; and 3) The Chandler Wobble measured by GRACE and GRACE Follow-On. The purpose of the research is to assess 1,2 and 3 and recommend a solution to re-compute the GRACE and GRACE Follow-On Datasets.

\section{Data, Methods and Techniques, and the GRACE Flaw}

Data for water equivalent mass change (i.e. terrestrial water transient storage) comes from Release-05 (R5) Level-3 products provided by the GRACE Science Team centers and Release-06 from GRACE Follow-On Science Team center. Previous releases R2 through R4 and R5 have been investigated [22]-[32]. Grids are produced at 1-arc-degree global coverage complete to degree and order 40 . The GRACE solution to the gravity potential formulated as water equivalent mass change (length scale, $\Delta h$ ) can be expressed in the harmonic expansion given by

$$
\Delta h(\varnothing, \lambda, t)=\rho \sum_{l=0}^{40} \sum_{m=0}^{l} \frac{(2 l+1)}{1+k_{l}} W_{l} P_{l m} \sin (\varnothing) \Delta f_{l m}
$$

with

$$
\begin{gathered}
\rho=\frac{a_{e} \rho_{e}}{3 \rho_{w}} \\
W_{l}=\exp \left[\frac{\left(\operatorname{lr} / a_{e}\right)^{2}}{4 \ln (2)}\right] \\
\Delta f_{l m}=\Delta C_{l m}(t) \cos (m \lambda)+\Delta S_{l m}(t) \sin (m \lambda)
\end{gathered}
$$

and coefficients $P_{l m}$ : Normalized Legendre polynomials, $\Delta C_{l m}(t)$, and $\Delta S_{l m}(t)$ : Normalized time-varying Stokes spherical harmonic geopotential coefficients, $\mathrm{a}_{\mathrm{e}}$ : Earth mean radius, $r$ : spatial radius, $k_{t}$. Love numbers, $\rho_{e}$ : Earth mean density, $\rho_{w}$ : fresh water density, t: time, and $\varphi, \lambda$ are latitude and longitude [33]. Beyond degree (order) 40 to 70 , the inherent noise level in the mass change signal becomes significant [34]. Processing includes downward propagation and adjustments to remove the time-variable mass change effects from ocean tides, atmosphere variance and mean variation (the GRACE geoid model). Low-order Stokes spherical harmonic geopotential coefficient derived by the International Lunar Ranging Service (NASA-Goddard and International Earth Rotation Service) and In- 
ternational Terrestrial Reference Frame are used, Figure 1 [35] [36]. A normalized Gaussian smoother filter mitigates striping artifacts produced by the orbit non-crossing and control-descent geometry [33] [34]. Differences in processing (de-aliasing) and error sources and products are attributable to differences in assumed zero-degree and order Stokes harmonics, tide (ocean) models and the modeled atmosphere mass change removal, respectively in decreasing order of magnitude [37] [38].

GRACE global coverage presented here is from August 2002 through December 2020. Glacial Isostatic Adjustment (GIA) is a global phenomenon by way of mantle flow following the decay of the Pleistocene ice sheets in North America and Euro-Scandinavia [39]. GIA is removed from the GRACE grids [40].

The GRACE satellites (A and B of GRACE and C and D of GRACE Follow-On) cover their twin-orbit spheres in about 28-days (i.e. close to the Sidereal month). This global "measure-month" represents a periodic sampling signal (i.e. alias) that repeats every 12 months [41] [42] [43].

The flaw in GRACE, illustrated in Figure 2, is that the harmonic expansion is an Earth-centric, i.e. Geocentric, field reference with mean radius, mean density and Love numbers pertaining to only the Earth. GRACE assumes a One-Body gravity field, not the real Two-Body gravity field. The Stokes harmonic field potentials for the Moon had been estimated from early satellite tracking data and laser ranging up to the 1980s [44]. However, quality of the harmonics of degree 4 and higher were considered low and many questions remained regarding the

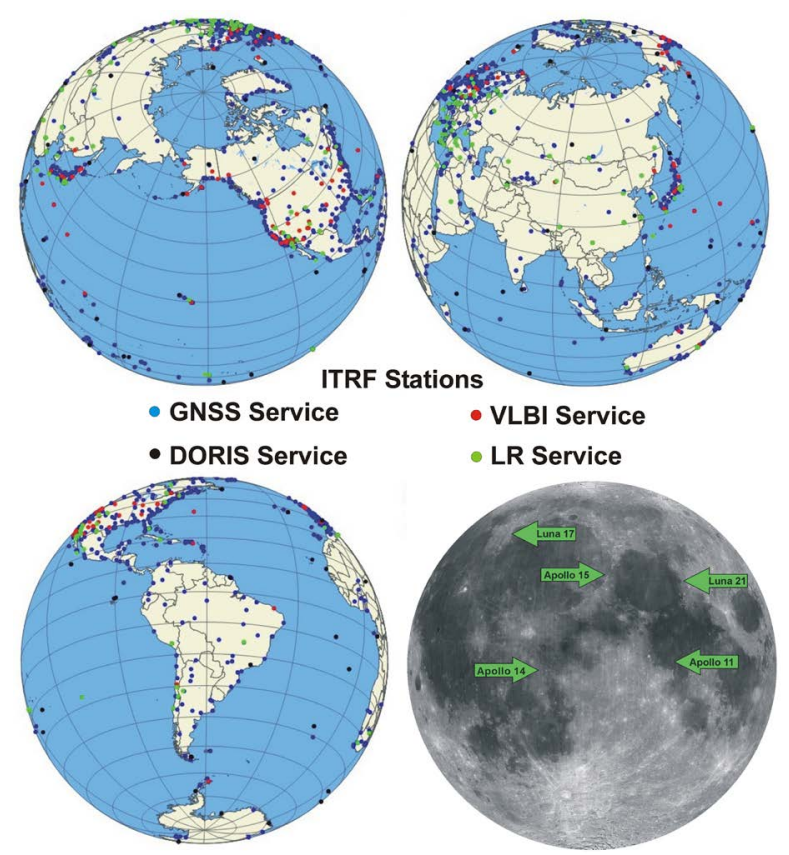

Figure 1. ITRF Stations. The ITRF combines multi-satellite-sensors and ground stations laser measurements from the international services of the Global Navigation Satellite System, Doppler Orbitography and Radiopositioning Integrated by Satellite (DORIS), Very-Long Baseline Interferometry (VLBI) [35] and the Lunar Ranging Service (LR) that was established by Apollo Missions 11, 14 and 15 with Russian Space Missions Luna 17 and 21 [36]. 


\section{Geocenter System (G)}

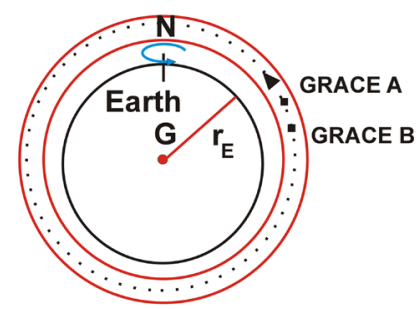

Geodesic Equipotentials

Barycenter System $(\beta)$

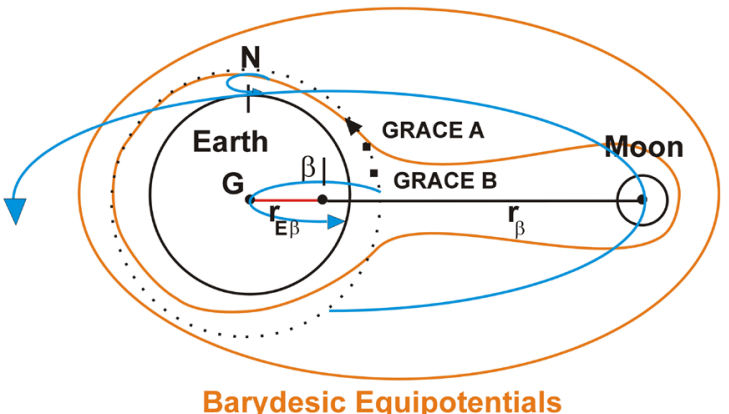

Figure 2. Barycenter-Geocenter Comparison. The illustration compares the gravity fields and orbit geometries of the Barycenter versus the Geocenter Systems (not to scale), with the GRACE and GRACE Follow on (A and B and C and D, respectively) managed geocentric orbits. Notation as follows: N-rotation axis, G-Geocenter, $\beta$-Barycenter, $\mathrm{r}_{\mathrm{e}}$-radius of earth, $\mathrm{r}_{\mathrm{e}} \beta$-radius of Barycenter in earth's mantle, $\beta$-Barycenter rotation axis and $\mathrm{r}_{\beta}$-radius of Moon to Barycenter in Earth's mantle.

offset of the Moon's gravity center to the center of figure, the topography and density variations of the farside and nearside [44]. Recall that the Moon is in a locked-orbit with Earth with mass concentrated on the nearside. Therefore during the GRACE mission development the Stokes harmonic field potentials of the Moon were not used.

Consider the following thought experiment. Assume the Earth is a perfect and homogenous sphere (no internal mass variation, not visco-elastic) and there is no Moon. As the GRACE satellites orbit at about $400 \mathrm{~km}$ above the Earth, their path is a geodesic (Earth-centered) defined by their angular momentum. As the GRACE satellites range their intra-satellite distance (by KBR), there is no variation with the exception of electronic-system induced errors. Introduce a mass, the Moon, at a distance (ellipsoidal orbit) of roughly $240,000 \mathrm{~km}$ away from Earth with a mass of about 1/81 Earth mass. The gravity field in this case is no longer Geocentric it is Barycentric. The GRACE satellite's orbits are maintained Geocentric. The KBR-measured intra-satellite range varies, because the GRACE satellite orbits cross Barydesics, equipotentials of the Barycentric Earth-Moon gravity field [45]. In this case the perfect Earth and Moon co-orbit the Barycenter, $1650 \mathrm{~km}$ within the perfect Earth (about $4728 \mathrm{~km}$ outward along the Earth's radius) on a Sidereal monthly rate of 27.32 days [46]. If the GRACE satellites as they are ranging by KBR the intra-satellite distance could cover the 
perfect Earth in their orbits within about 1 hour, the principle harmonics they would "measure" would be 1 hour, 24 hours, one Sidereal month and one Sidereal year, repeated over the mission life time. Yet, as the GRACE satellite's KBR's measure the inter-satellite distance, the GRACE orbits are crossing Barydesic equipotentials, causing apparent accelerations and decelerations caused by the maintained-Geocentric orbits. Sampling errors, i.e. aliases (by way of the Shannon-Nyquist theorem), are not geophysical signals.

\section{Discussion}

The Chandle Wobble (CW) is an excited resonance and the Annual Wobble (AW) a forced resonance of the Earth's rotation axis [47]. Both are recognized as periodic variations of Polar Motion [48]. Polar motion, a.k.a. the "variation latitude" and the variation of star zeniths (local plumb line from observer to star), have been known since antiquity by astrometry. L. Euler mathematically solved the problem of polar motion in 1765 . His analytical Free-unforced nutation of the rotation axis solution gave a period of 305 days and would dissipate in 68 years [47] [48]. The empirical measurement and physical cause remained elusive until F. Küster in 1888 and S. Chandler in 1891 produced the first accurate measurements, 428 days (Chandler, 1891/92, with Free and Forced-annual components), and a hypothesis [47] [48].

During the $20^{\text {th }}$ century refinements by way of advances in instrumentation and ground networks (including the Lunar Ranging sites on the Moon) have focused analysis on the components (prograde and retrograde) and variability (amplitude and period) of the CW and AW of Polar Motion [47] [48]. Recent measurements have shown the instantaneous periods of the CW and AW (prograde) are 392 to 441 days and 359 to 370 days, respectively [47]. Interestingly, the amplitude of CW has varied from 43 to 287 mas (milli-arc seconds) and is following a decreasing trend since 1995 [47]. The amplitude of AW (prograde) has varied from 65 to 180 mas and is following a decreasing trend since 2010 (the AW retrograde component has been oscillating since 1960) [47].

Chandler (1893) followed his discovery of the CW and AW components of Polar Motion as observed by star zeneth variations, i.e. the "latitude variation", with his hypothesis that the CW was caused by the "Free nutation motion" of the rotation axis within the Earth [48] [49]. However, a "Free nutation" of the rotation axis would quickly dissipate as Euler (1765) analytically calculated [47] [48]. Investigations in the first half of the $20^{\text {th }}$ century proposed hypotheses for AW as "logically evident" but untestable such as mantle anelasticity, inner and outer core variable rotations, tectonic motions of convecting-mantle and outer core mantle-jets, i.e. hot-spot plumes, solar and jupiter-saturn planetary gravitational torques, electromagnetic torques generated by the liquid outer core producing interference with the lower mantle magnetic field, and perturbations by large magnitude earthquakes [50] [51]. Late $20^{\text {th }}$ and early $21^{\text {st }}$ century investigations looked to causative interpretations of AW by variations of atmospheric mass, glacial-eustacy, ocean bottom 
pressure and terrestrial water transient storage [47] [51]. However, as testable hypotheses and valid measurements remain elusive, such interpretations particularly with regard to terrestrial water transient storage are suspect

\subsection{A Test of GRACE}

A question now arises regarding the GRACE mission. Other than the KBR measured inter-satellite range and range rate, what physical property of the Earth can the GRACE satellites possibly measure? To evaluate this question three test regions of Earth have been selected for investigation: the Alaska North Slope, Amazon River Basin and Qinghai-Tibet Plateau. These regions have unique environments, geology-tectonics, hydrology and topography against which the GRACE R06 (described earlier) will be evaluated for regionalized spectral power and harmonic content, Figure 3.

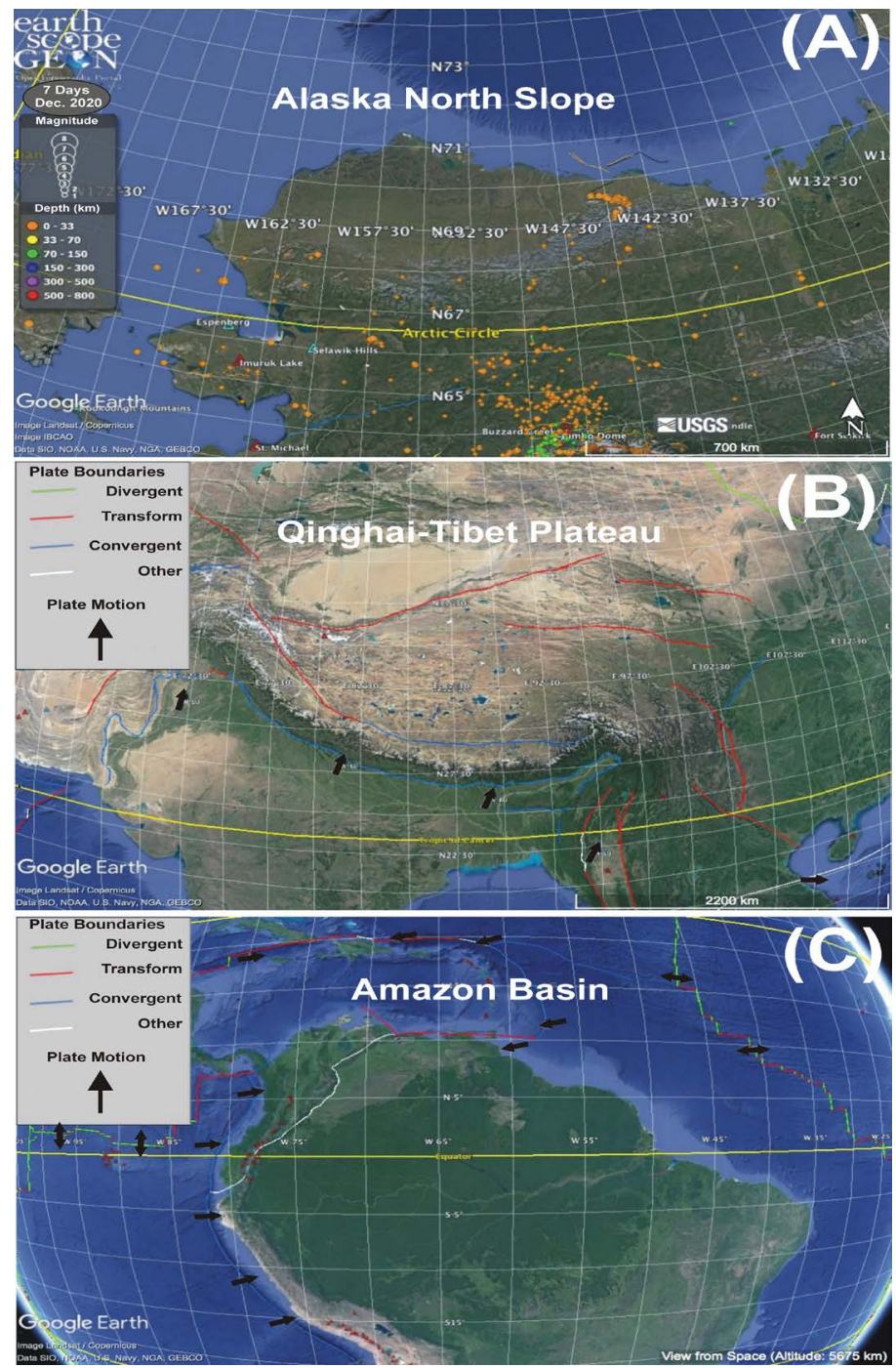

Figure 3. Global Test Regions. Seismicity, Holocene volcanos and tectonic plate boundries coutersy of UNAVCO (EarthScope GEON, NSF, NASA) and USGS illustrated in Google Earth. 


\subsection{Alaska North Slope}

The Alaska North Slope is the most extensive arctic environment region of the United States. The surface from the Brooks Range to the Chukchi and Beaufort Sea coasts is one of continuous permafrost up to 600 meters thick, tundra vegetation and extensive rivers that is home to indigenous peoples, Caribou and Muskox herds, summer wetlands supporting wild fowl and extensive winter thaw lakes [52] [53] [54] [55] [56]. Beneath the Holocene-Pleistocene permafrost (gravels, silts and ground ice) is a vast Permian-to-Miocene foreland fault/fold orogen structurally connected to the Paleozoic-Mesozoic formations of the Brooks Range [57]-[63]. At depths of in excess of 600 meters, the geologic structures are sources of gas and oil that support operational productions as at Purdue Bay and exploration activates [58] [63] [64]. Petroleum reserves make this region one of America's largest and of National strategic and world importance [65]. Since the Quaternary the Alaska North Slope has been a passive continental margin of the North American Plate. The ocean portion of the North American plate meets the divergent boundary at the Gakkel Ridge (spreading rift) in the Arctic Ocean basin, Figure 4(A) [66] [67]. North Slope earthquake activity is typically in the 1 to 3 -magnitude range and at depths to 33 kilometers occurs daily distributed mostly in the Brooks Range and elsewhere [68] [69].

\subsection{Qinghai-Tibet Plateau}

The Hindu Kush-Karakoram-Himalayas, Tian Shan Mountains with the Qinghai-Tibet Plateau and Tarim Basin form a region of more than 3.4 million square kilometers [22]-[28] [68]. Home to numerous large lakes and tarns (glacier lakes), and to more than 50,000 glaciers and high-elevation snowfields, continuous permafrost and the Taklimakan desert this region is the source of the Indus, Ganga, Brahmaputra, and Yamuna Rivers, the Indo-Gangetic River system [70] [71] [72]. The Himalayan Mountains and associated ranges create a boundary separating westerly continental air masses and southerly marine air masses of the summer South Asian monsoon [73] [74]. The long-term seasonal stationarity of these air masses against the high mountains gives rise to anomalous atmospheric mass variations with abundant precipitation [75]. The mean elevation of the plateau is about 4500 meters above mean sea level, which affects broadband solar and infrared-thermal fluxes of the atmosphere above the plateau [76]. The broad plateau high elevation is due to the subduction of the India plate beneath the Eurasia plate from about 55 million years ago (Late Cretaceous) and is on going, Figure 4(B) [77] [73]. With more than 30-years of GPS and recently GNSS (GPS and GLONASS) geodetic measurements it is know that the plateau is rising at about $8 \mathrm{~mm}$ per year, on average, and which in southern Tibet becomes about 17 to $22 \mathrm{~mm} / \mathrm{yr}$ [78] [79] [80]. However, failure to account for the anomalous atmospheric mass variations and the mantle mass transport has given rise to many dubious conclusions raised in poorly researched scientific papers [27]. 


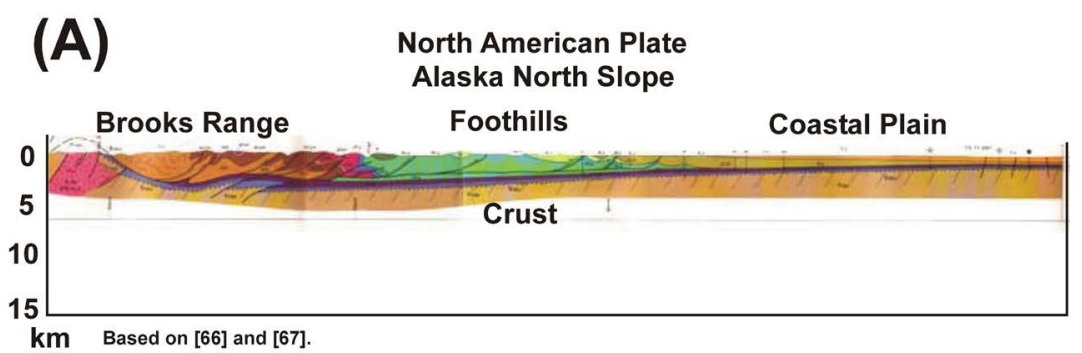

\section{(B)}
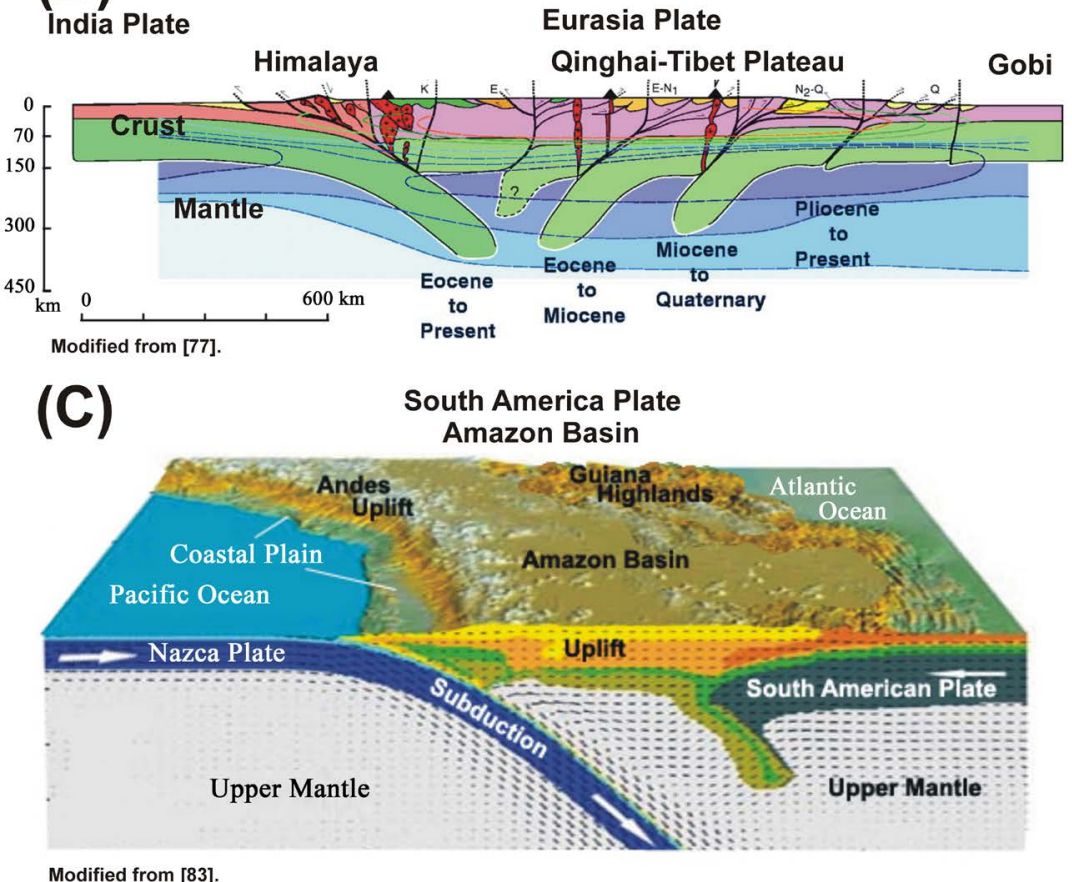

Figure 4. Geologic-Plate Tectonic cross-sections of the Alaska North Slope, Qinghai-Tibet Plateau and the Amazon Basin (South American Plate).

\subsection{Amazon Basin}

The Amazon basin, the Amazon River and tributaries, drains an area in excess of $35 \%$ of the continent of South America the land portion of the South American Plate [81] [82]. Its area is estimated at $6,300,000 \mathrm{~km}^{2}$. From the high elevation Andes Mountains, the result of subduction of the Fallon (former) and Nazca Plates in the west, the modern Amazon spans to the Atlantic Ocean in the east where the ocean portion of the plate continues to the boundary with the Mid-Atlantic Ridge, Figure 4(C) [83] [84] [85].

The Amazon rainforest and transcontinental river system are the largest on Earth [82]. Many of the flora and fauna of modern Amazonia date from lineages as old as Late Cretaceous to Paleogene, 100 to 23 million years ago, coeval with the subduction of the India Plate with the Eurasia Plate and the rising of the Himalayas and Qinghai Plateau. The main geological events associated with stream capture that formed the modern transcontinental rives system are estimated to have occurred in the Neogene. While much of the present day topo- 
graphy of basins and mountains can be explained by Plate Tectonics there is mounting evidence that viscous flow within the mantle, a transient mass, plays a significant role in the topography of river systems such as the Amazon, the Brahmaputra and others [86].

\subsection{Tests by Regional Power Sectral Density}

Figure 5 shows the GRACE water equivalent mass change time-series, Periodograms and Power Spectral Density of the test regions from August 2002 through January 2017. The time-series are the regionalized (volumes) for the Alaska North Slope, Qinghai-Tibet Plateau and Amazon, respectively. Inspection of the time-series, periodograms and power spectra reveals remarkable similarities! The Periodogram and Powe Spectral Density are Red-Noise on each of the Test Regions. The reader will note the magnitude (Periodogram score and Power $\mathrm{dB}$ ) of the changes rise as the area of regionalization (area) increases, from Alaska North Slope to Amazon. The Power Spectral Density of the time-series black line and the estimate of significance (90\%) using Chi-square $\chi^{2}$ process red line with the time-series covariance shows very low significance except for the 12 sideral month signal. The 12-month signal may be an alias of the Chandler Wobble (14.23-month period) [50] [51] [87] [88].

\section{Results}

\subsection{Results: Alaska North Slope}

The highest Periodogram scores occur near the 2-month (Sideral Months) start of the series: an artifact of GRACE orbit sampling. Two components at 11.636 and 12.190 months have low scores 75.703 and 25.476 (at 0.082 and 0.086 frequency), respectively. Power Spectral Density of these two components is 19.912 and $21.285 \mathrm{~dB}$, and above the model-noise level (significance better than 90\%). These components are not the AW. Components where CW should be in the Periodogram at 14.222 sideral months has a very low score of 0.478 and in the Power Density Spectrum at 0.070 frequency has $14.823 \mathrm{~dB}$ of low significance, Figure 5(A).

\subsection{Results: Qinghai-Tibet Plateau}

Components in the Periodogram at 2 and 2.032 Siderial months have score of $4.5 \mathrm{E} 5$ and $8.5 \mathrm{E} 5$, respectively. Power Spectral Density at 0 and 0.012 frequency is 37.285 and $34.801 \mathrm{~dB}$, respectively. These components are aliases produced by the GRACE orbital sampling. Where the AW should be in the Periodogram at 11.326 and 12.190 Siderial months have scores of 2.0E7 and 1.6E7, respectively. Power Spectral Density of these components is 39.23 and 39.35 $\mathrm{dB}$ (at 0.082 and 0.086 frequency), respectively. In the Periodogram where the CW should be at 14.222 Siderial months the component has a score of 4.7E4. In Power Spectral Density at corresponding frequency 0.070 the power is $31.473 \mathrm{~dB}$, Figure 5(B). 

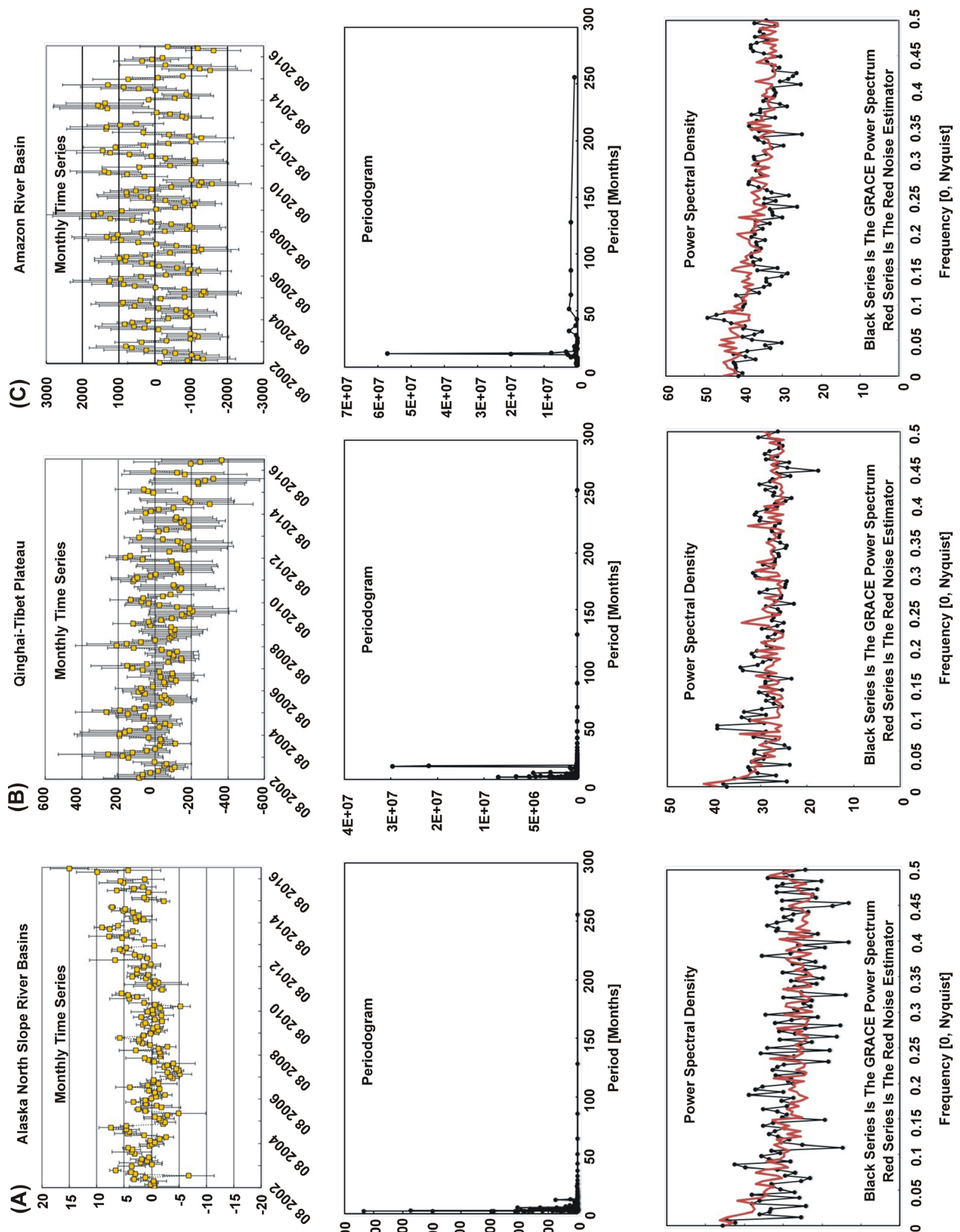

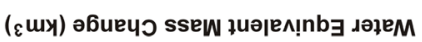
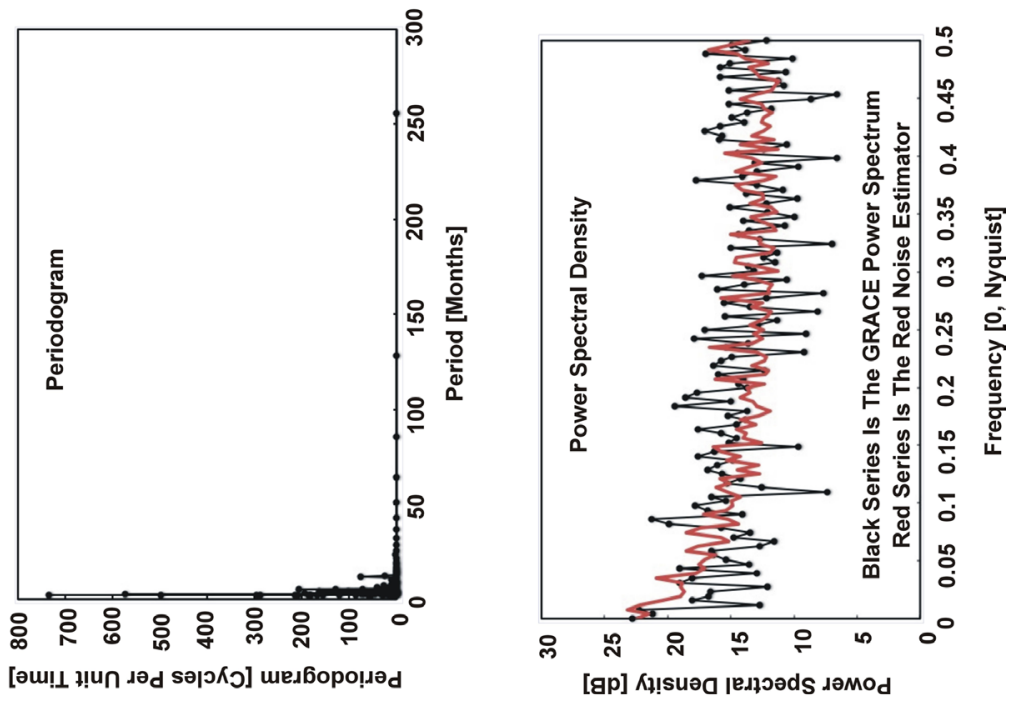

Figure 5. GRACE Regional Time Series, Periodogram and Power Spectral Density of the Test Regions Alaska North Slope, Qinghai-Tibet Plateau and Amazon Basin. The Red-series in the Power Spectral Density represents the Chi-Square $\left(\chi^{2}\right)$ red-noise significance estimate (90\%) based on the covariance of the regional time series. For processing, the GRACE time series are zero-padded to 256 (28) to satisfy the Discrete Fast Fourier Transform requirement. 


\subsection{Results: Amazon Basin}

Components in the Periodogram at 2 and 2.016 Sidereal months have score of 4.9E4 and 2.3E5, respectively. Power Spectral Density at 0 and 0.004 frequency is 41.311 and $40.300 \mathrm{~dB}$, respectively. As with the Qinghai-Tibet Plateau, these components are aliases produced by the GRACE orbital sampling. Where the AW should be in the Periodogram at 11.326 and 12.190 Siderial months have scores of 2.0E7 and 5.7E7, respectively. Power Spectral Density of these components is 49.317 and $47.049 \mathrm{~dB}$ (at 0.082 and 0.086 frequency), respectively. In the Periodogram where the $\mathrm{CW}$ should be at 14.222 Sidereal months the component has a score of 6.6E4. In Power Spectral Density at corresponding frequency 0.070 the power is $39.899 \mathrm{~dB}$, Figure $5(\mathrm{C})$.

\subsection{Summary of Results}

The actual physical dissimilarities of the regions are stark: two regions, the Alaska North Slope and the Qinghai Plateau have minimal vegetation and substantial permafrost and snow cover whereas the Amazon region has no permafrost, almost no snow cover except for the high elevations and very substantial vegetation! Furthermore, the near-surface and crustal geology of each region is very different, and they reside on different tectonic plates with very different velocity fields!

The only physical property of Earth that is the same in the three test regions that GRACE can measure is the Chandler Wobble, the variation of Earth's rotational axis, excited and forced, from torques primarily in the Earth's mantle and gravity fields (primarily the Barycenter field). The AW is unfortunately not resolvable, i.e. separately from the CW, by GRACE due to aliasing (the GRACE Flaw) and not significant in comparison to inherent noise (Figure 5).

\section{Conclusions}

This report assesses the GRACE flaw in the GRACE and GRACE Follow-On mission design, the CW and the aliased AW (Polar Motion components) and their effects on the current global GRACE datasets. Furthermore, at present the only physical property of the Earth that GRACE can possibly measure the Chandler Wobble, though at this time it is not measured accurately. From the analysis presented here of the GRACE satellite orbits and spectral analysis of the datasets, our main conclusion is that the annual harmonic component, Figure 5, is not the AW of Polar Motion, but rather an alias artifact of orbital sampling from the KBR measurements (i.e. orbital mechanics and instrument ranging sampling rates). By deduction, we must conclude that interpretations of terrestrial water transient storage derived from GRACE are currently wrong.

Therefore, to correct the GRACE Flaw, a new two-body Barycentric field solution and two-body harmonic expansion are called for. It is proposed that such is achievable using the Moon Stokes coefficients and parameters derived from the Gravity Recovery Interior Laboratory (GRAIL) mission [89]. Furthermore, this 
will resolve the GRACE Flaw in the original GRACE missions and allow for the refinement of the CW and resolution of the AW in GRACE datasets following the works of Lambeck [50] [51], Xie and Kopeikin [45], Adhikari and Ivins [87] and Lambert and Sottili [88].

\section{Acknowledgements}

Research was supported by grants NASA NNOG6M48G, NNX17AC57A and NSF ARC0632400, ARC-0612533, ARC0856864 and EPS-0701898. Thanks to the Geophysical Institute and the International Arctic Research Center colleagues and employees at the University of Alaska Fairbanks and colleagues at the State Key Laboratory of Frozen Soil Engineering, Chinese Academy of Sciences at Lanzhou, Gansu, China.

\section{Conflicts of Interest}

The author declares no conflicts of interest regarding the publication of this paper.

\section{References}

[1] Barnes, P.W. and Reimnitz, E. (1976) Flooding of Sea Ice by Rivers of Northern Alaska. In: Williams Jr., R.S. and Carter, W.D., Ed., ERTS-1 A New Window on Our Planet, Paper 929, U.S. Geological Survey, Washington DC, 356-359.

[2] United States Geological Survey (1997) Landsat Data, USGS Fact Sheet 084-97. United States Geological Survey, Washington DC.

[3] Tifford, S.G., Asrar, G. and Bucklund, P.W. (1994) Mission to Planet Earth. Advances in Space Research, 14, 5-9. https://doi.org/10.1016/0273-1177(94)90339-5

[4] Encyclopedia (2020) Mission to Planet Earth (NASA). https://www.encyclopedia.com/environment/encyclopedias-almanacs-transcripts-a nd-maps/mission-planet-earth-nasa

[5] Saltzman, B. (1983) The Theory of Climate. Advances in Geophysics, 25, iii-xii, 3-505.

[6] Memorandum of Understanding (1989) Memorandum of Understanding between the United Nations Environment Programme (UNEP) and The World Meteorological Organization (WMO) on The Intergovernmental Panel on Climate Change (IPCC). The Intergovernmental Panel on Climate Change, Geneva. https://www.ipcc.ch/site/assets/uploads/2019/06/MOU between UNEP and WM O on IPCC-1989.pdf

[7] Houghton, J.T., Jenkins, G.J. and Ephraums, J.J. (1990) Climate Change: The IPCC Scientific Assessment. Cambridge University Press, Cambridge.

[8] NRC (National Research Council) (1991) Opportunities in the Hydrologic Sciences. National Academies Press, Washington DC.

[9] NRC (National Research Council) (1999) Appendix C in "Assessment of NASA's Plans for Post-2002 Earth Observing Missions". NASA's Associate Administrator for Earth Science, Washington, D.C.

[10] Houghton, J.T., Ding, Y., Griggs, D.J., Noguer, M., van der Linden, P.J., Dai, X., Maskell, K. and Johnson, C.A. (2001) Climate Change 2001: Scientific Basis. Cambridge University Press, New York.

[11] NRC (National Research Council) (2005) Earth Science and Applications from 
Space: Urgent Needs and Opportunities to Serve the Nation. National Academies Press, Washington DC.

[12] Haq, B.U., Hardenbol, J. and Vail, P.R. (1987) Chronology of Fluctuating Sea Levels Since the Triassic (250 Million Years Ago to Present). Science, 235, 1156-1167. https://doi.org/10.1126/science.235.4793.1156

[13] Vail, P.R., Mitchum Jr., R.M., Todd, R.G., Widmier, J.M., Thompson III., S., Sangree, J.B., Bubb, J.N. and Hatlelid, W.G. (1977) Seismic Strati-Graphy and Global Changes of Sea Level. In: Payton, C.E., Ed., Seismic Stratigraphy-Applications to Hydrocarbon Exploration, Vol. 26, American Association of Petroleum Geology Memoir, Tulsa, 49-212.

[14] Hallam, A., Cohen, J.M. and Gilbert Chaloner, W. (1989) The Case for Sea-Level Change as a Dominant Causal Factor in Mass Extinction of Marine Invertebrates. Philosophysical Transactions of the Royal Society B, 325, 437-455. https://doi.org/10.1098/rstb.1989.0098

[15] Miller, K.G., Mominz, M.A., Browing, J.V., Wright, J.D., Mountain, G.S., Katz, M.E., Sugarman, P.J., Cramer, B.S., Christie-Blick, N. and Pekar, S.F. (2005) The Phanerozoic Record of Global Sea-Level Change. Science, 310, 1293-1298. https://doi.org/10.1126/science.1116412

[16] Haq, B.U. and Schutter, S.R. (2008) A Chronology of Paleozoic Sea-Level Changes. Science, 322, 64-68.

[17] Ronov, A.B. (1994) Phanerozoic Transgressions and Regressions on the Continents: A Quantitative Approach Based on Areas Flooded by the Sea and Areas of Marine and Continental Deposition. American Journal of Science, 294, 777-801. https://doi.org/10.2475/ajs.294.7.777

[18] Scotese, C.R. (2002) Analysis of the Temperature Oscillations in Geological Eras. W.H. Freeman \& Company, New York.

[19] Pagani, M., Zachos, J.C., Freeman, K.H., Tipple, B. and Bohaty, S. (2005) Marked decline in atmospheric carbon dioxide concentrations during the Paleogene. Science, 309, 600-603. https://doi.org/10.1126/science.1110063

[20] Rudman, W.F. (2014) Earth's Climate: Past and Future. 3rd Edition, W.H. Freeman \& Company, New York.

[21] Kent, D.V., Olsen, P.E., Rasmussen, C., Lepre, C., Mundil, R., Irmis, R.B., Gehrels, G.E., Giesler, D., Geismann, J.W. and Parker, W.G. (2018) Emperical Evidence for Stability of the 405-Kiloyear Jupiter-Venus Eccentricity Cycle over Hundreds of Millions of Years. Proceedings of the National Academy of Sciences of the United States of America, 115, 6153-6158. https://doi.org/10.1073/pnas.1800891115

[22] Muskett, R.R. (2008) GRACE Equivalent Water Mass Balance of the Himalayas and Tibet Plateau Region. Geophysical Research Abstracts, 10, 01606, 1607-7962/gra/ EGU2007-A-01606, European Geoscience Union Meeting, Vienna.

[23] Muskett, R.R. (2008) GRACE Secular Trends and Periodic Variations at Global and Regional Scales. Geophysical Research Abstracts, 10, 01592, 1607-7962/gra/EGU2007A-01592, European Geoscience Union Meeting, Vienna.

[24] Muskett, R.R. (2008) GRACE Hydrologic Mass Balance Secular Trends and Variations on Arctic Permafrost Watersheds. EOS Transactions of the American Geophysical Union, 89, GC41A-0690.

[25] Muskett, R.R. (2009) Hydrologic Secular Trends and Variations of the Eurasian and North American Permafrost Watersheds from GRACE, SSM/I and AMSR-E Observations. Geophysical Research Abstracts, 11, EGU2009-0, European General Assembly 2009, Vienna. 
[26] Muskett, R.R. (2010) Eastern Eurasian and Western North American Permafrost Groundwater Storage Changes from GRACE and High-Resolution Geoid Models. Geophysical Research Abstracts, 12, EGU2010-1596, EGU General Assembly 2010, Vienna.

[27] Muskett, R.R. (2010) High-Resolution Geoid-Derived Groundwater Storage Changes in Alaska, U.S.A. and Yukon Territory, Canada, from 1999 through 2009 with Comparison to GRACE. Geophysical Research Abstracts, 12, EGU2010-1595, 2010 EGU General Assembly, Vienna.

[28] Muskett, R.R. (2010) Water Mass Loss of the Himalayas from GRACE, ICESat and SRTM. Geophysical Research Abstracts, 12, EGU2010-1037, 2010 EGU General Assembly, Vienna.

[29] Muskett, R.R. and Romanovsky, V.E. (2009) Groundwater Storage Changes in Arctic Permafrost Watersheds from GRACE and in Situ Measurements. Environmental Research Letters, 4, Article ID: 045009. https://doi.org/10.1088/1748-9326/4/4/045009

[30] Muskett, R.R. and Romanovsky, V.E. (2011) Alaskan Permafrost Groundwater Storage Changes Derived from GRACE and Ground Measurements. Remote Sensing, 3, 378-397. https://doi.org/10.3390/rs3020378

[31] Muskett, R.R. and Romanovsky, V.E. (2011) Energy and Mass Changes of the Eurasian Permafrost Regions by Multi-Satellite and in Situ Measurements. Natural Science, 3, 827-836. http://dx.doi.org/10.4236/ns.2011.310108

[32] Muskett, R.R. and Romanovsky, V.E. (2012) Multi-Satellite-Derived Changes in Energy and Mass of Russian Permafrost Regions. Proceedings of the 10 th International Conference on Permafrost, Salekhard, 25-29 June 2012, 277-282.

[33] Wahr, J., Molenaar, M. and Bryan, F. (1998) Time Variability of the Earth's Gravity Field: Hydrologic and Oceanic Effects and Their Possible Detection Using GRACE. Journal of Geophysical Research: Solid Earth, 103, 30205-30229. https://doi.org/10.1029/98JB02844

[34] Tapley, B.D., Bettadpur, S., Watkins, M. and Reigber, C. (2004) The Gravity Recovery and Climate Experiment: Mission Overview and Early Results. Geophysical Research Letters, 31, Article ID: L09607. https://doi.org/10.1029/2004GL019920

[35] International Earth Rotation and Reference Systems Service (2021) Map of ITRF2014 Network. https://www.iers.org/IERS/EN/DataProducts/ITRF/map/itrfmap.html

[36] Lunar Laser Ranging Service (2019) Lunar Laser Ranging. https://ilrs.gsfc.nasa.gov/science/scienceContributions/lunar.html

[37] Quinn, K.J. and Ponte, R.M. (2010) Uncertainty in Ocean Mass Trends from GRACE. Geophysical Journal International, 181, 762-768.

https://doi.org/10.1111/j.1365-246X.2010.04508.x

[38] Zenner, L., Gruber, T., Jäggi, A. and Beutler, G. (2010) Propagation of Atmospheric Model Errors to Gravity Potential Harmonics-Impact on GRACE Dealiasing. Geophysical Journal International, 182, 797-807. https://doi.org/10.1111/j.1365-246X.2010.04669.x

[39] Peltier, W.R. (2004) Global Glacial Isostasy and the Sur-Face of the Ice-Age Earth: The ICE-5G (VM2) Model and GRACE. Annual Reviews Earth \& Planetary Science, 32, 111-149. https://doi.org/10.1146/annurev.earth.32.082503.144359

[40] Paulson, A., Zhong, S. and Wahr, J. (2007) Inference of Mantle Viscosity from GRACE and Relative Sea Level Data. Geophysical Journal International, 171, 497-508. https://doi.org/10.1111/j.1365-246X.2007.03556.x

[41] Jenkins, G.M. and Watts, D.G. (1969) Spectral Analysis and its Applications. Emer- 
son-Adams Press, Inc., Boca Raton.

[42] Box, G.E.P. and Jenkins, G.M. (1875) Time Series Analysis: Forecasting and Control. Revised Edition, Holden-Day, San Francisco.

[43] Press, W.H., Teukolsky, S.A., Vetterling, W.T. and Flannery, B.P. (2007) Numerical Recipes: The Art of Scientific Computing. 3rd Edition, Cambridge University Press, Cambridge.

[44] Phillips, R.J. and Lambeck, K. (1980) Gravity Fields of the Terrestrial Planets: Long-Wavelength Anomalies and Tectonics. Reviews of Geophysics and Space Physics, 18, 27-76. https://doi.org/10.1029/RG018i001p00027

[45] Xie, Y. and Kopeikin, S. (2010) Post Newtonian Reference Frames for Advanced Theory of the Lunar Motion and a New Generation of Lunar Laser Ranging. Acta Physica Slovaca, 60, 393-495.

[46] Stacey, F.D. (1977) Physics of the Earth. 2nd Edition, Wiley \& Sons Inc., New York.

[47] Wang, G., Liu, L., Su, X., Liang, X., Yan, H., Tu, Y., Li, Z. and Li, W. (2016) Variable Chandler and Annual Wobbles in Earth's Polar Motion. Survey of Geophysics, 37, 1075-1093. https://doi.org/10.1007/s10712-016-9384-0

[48] Dick, S.J. (2000) Polar Motion: A Historical Overview on the Occasion of the Centiennial of the International Latitude Service. International Astronomical Union Colloquium, 178, 1-24. https://doi.org/10.1017/S0252921100061170

[49] Kiryan, D.G. and Kiryan, G.V. (2014) Moon's Perigee Mass as a Missing Component of the Earth's Procession-Nutation Theory. Proceedings in Applied Mathematics and Mechanics, 14, 49-60. https://doi.org/10.1002/pamm.201410017 https://arxiv.org/pdf/1109.4969

[50] Lambeck, K. (1980) The Earth's Variable Rotation: Geophysical Causes and Consequences. Cambridge University Press, Cambridge.

https://doi.org/10.1017/CBO9780511569579

https://www.google.com/books/edition/The Earth s Variable Rotation/-kiG3uYk oUEC?hl=en \&gbpv $=0$

[51] Lambeck, K. (1988) The Earth's Rotation and Reference Frames for Geodesy and Geodynamics. Proceedings of the 128th Symposium of the International Astronomical Union, Coolfont, 20-24 October 1986, 1-20.

[52] Jorgenson, T., Yoshikawa, K., Kanevskiy, M., Shur, Y., Romanovsky, V., Marchenko, S., Grosse, G., Brown, J. and Jones, B. (2008) Map of Permafrost Characteristics of Alaska. Institute of Northern Engineering, University of Alaska Fairbanks, Fairbanks.

[53] Jorgensen, T. (2008) Site \#9 Thermokarst Pits and Fens in Coldstream Valley. In: Stevens, D.S.P., Ed., NICOP Local Field Trip Guidebook. Part I, Division of Geological \& Geophysical Surveys Guidebook, Vol. 11, Alaska Department of Natural Resources, Juneau, 3-37.

[54] Coulter, H.W., Hopkins, D.M., Karlstrom, T.N.V., Pewe, T.L., Wahrhaftig, C. and Williams, J.R. (1962) Map Showing Extent of Glaciations in Alaska. MISC GEO INVEST MAP I-415, U.S. Geological Survey, Washington, DC.

https://doi.org/10.3133/i415

[55] Molnia, B.F. (2008) Glaciers of North America-Glaciers of Alaska. In: Williams, R.S., Jr., Ferrigno, J.G., Eds., Satellite Image Atlas of Glaciers of the World, Paper 1386-K, U.S. Geological Survey, Washington DC, 525 p. https://doi.org/10.3133/pp1386K

[56] Holland, K., Lilly, M., Schnabel, W., Toniolo, H. and Prokein, P. (2010) An Over- 
view of Available Research Results Related to Lakes Located within the Arctic Coastal Plain and North Slope Foothills Region, 2009. Bullen Point/Kuparuk Foothills Hydrology Projects Report No. INE/WERC 09-04, University of Alaska Fairbanks Institute of Northern Engineering, Fairbanks.

[57] Hanna, G.D. (1963) Oil Seepages on the Arctic Coastal Plain, Alaska. Paper 38, California Academy of Sciences, San Francisco.

[58] Collertt, T.S., Bird, K.J., Kvenvolden, K.A. and Magoon, L.B. (1989) Map Showing the Base to The Deepest Ice-Bering Permafrost as Determined from Well Logs, North Slope, Alaska. US Geological Survey Oil and Gas Investigations Map OM-222, U.S. Department of the Interior, Washington DC.

[59] Kirschner, C.E., Grantz, A. and Mullen, M.W. (1992) Impact Origin of the Avak Structure, Arctic Alaska, and Genesis of the Barrow Gas Fields. American Association of Petroleum Geologists Bulletin, 76, 651-679. https://doi.org/10.1306/BDFF889E-1718-11D7-8645000102C1865D

[60] Bird, K. (1999) Geographic and Geologic Setting in The Oil and Gas Resource Potential of the 1002 Area, Arctic National Wildlife Refuge, Alaska, by ANWAR Assessment Team. Open-File Report 98-34, US Geological Survey, Menlo Park.

[61] Collett, T.S., Agena, W.F., Lee, M.W., Zyrianova, M.V., Bird, K.J., Charpentier, R.R., Cook, Troy, Houseknect, D.W., Klett, T.R., Pollastro, R.M. and Schenk, C.J. (2008) Assessment of Gas Hydrate Resources on the North Slope, Alaska, 2008. US Geological Survey Fact Sheet 2008-3073, U.S. Department of the Interior, Washington DC. https://doi.org/10.3133/fs20083073

[62] Braund, S.R. and Associates (2009) Impacts and Benefits of Oil and Gas Development to Barrow, Nuiqsut, Wainwright, and Atqasuk Harvesters, Prepared for the North Slope Borough Department of Wildlife Management. State of Alaska, Department of Community and Economic Development, Division of Community Advocacy under the National Petroleum Reserve-Alaska (NPR-A) Impact Program, Juneau.

[63] Herriott, T.M., Wartes, M.A., Decker, P.L., Gillis, R.J., Shellenbaum, D.P., Mauel, D.J. and Helmold, K.P. (2015) Geologic Map of the Umiat-Gubik Area, Central North Slope, Alaska-Integration of Fieldwork and Subsurface Data in a Region of Known Oil and Gas Accumulations (Poster). Geological Society of America, Cordilleran Section Annual Meeting, Anchorage, 11-13 May 2015, Map PO-2015-002sh001. https://doi.org/10.14509/29442

[64] Banet Jr., A.C. (1991) Oil and Gas Developments on Alaska's North Slope: Past Results and Future Prospects. Open File Report 34, Bureau of Land Management, Anchorage.

[65] Spencer, A.M., Embry, A.F., Gautier, D.L., Stoupakova, A.V. and Sørensen, K., (2011) An Overview of the Petroleum Geology of the Arctic. Geological Society of London-Memoirs, 35, 1-15. https://doi.org/10.1144/M35.1

[66] Moore, T.E., Wallace, W.K., Bird, K.J., Karl, S.M., Mull, C.G., Dillon, J.T. (1992) Stratigraphy, Structure and Geologic Synthesis of Northern Alaska. Open-File Report 92-330, U.S. Geological Survey, Washington DC.

https://doi.org/10.3133/ofr92330

[67] Moore, T.E. and Box, S.E. (2016) Time-Slice Maps Showing Age, Distribution, and Style of Deformation in Alaska North of $60^{\circ}$ N. U.S. Open-File Report 2016-1138, Geological Survey, Washington DC. https://doi.org/10.3133/ofr20161138

[68] Saltus, R.W., Miller, E.L., Gaina, C. and Brown, P.J. (2011) Chapter 4 Regional Magnetic Domains of the Circum-Arctic: A Framework for Geodynamic Interpre- 
tation. Geological Society of London-Memoirs, 35,49-60. https://doi.org/10.1144/M35.4

[69] Mitchell, R.N., Kilian, T.M. and Evans, D.A.D. (2012) Supercontinent Cycles and the Calculation of Absolute Palaeolongitude in Deep Time. Nature, 482, 209-212. https://doi.org/10.1038/nature 10800

[70] Liu, X. and Chen, B. (2000). Climatic Warming in the Tibetan Plateau during Recent Decades. International Journal of Climatology, 20, 1729-1742. https://doi.org/10.1002/1097-0088(20001130)20:14\%3C1729::AID-JOC556\%3E3.0.C $\underline{\mathrm{O} ; 2-\mathrm{Y}}$

[71] Lou, D., Jun, H., He, R., Li, X., Muskett, R.R., Marchenko, S.S. and Romanovsky, V.E. (2018) Elevation-Dependent Thermal Regime and Dynamics of Frozen Ground in the Bayan Har Mountains, Northeastern Qinghai-Tibet Plateau, Southwest China. Permafrost and Periglacial Processes, 29, 257-270. https://doi.org/10.1002/ppp.1988

[72] Lou, D.L., Jun, H.J., He, R.X., Wang, X.F., Muskett, R.R., Marchenko, S.S. and Romanovsky, V.E. (2018) Characteristics of Water-Heat Exchanges and Inconsistent Surface Temperature Changes at an Elevational Permafrost Site on the Qinghai-Tibet Plateau. Journal of Geophysical Research Atmospheres, 123, 10057. https://doi.org/10.1029/2018JD028298

[73] Gadgil, S., Vinayachandran, P.N., Francis, P.A. and Gadgil, S. (2004) Extremes of the Indian Summer Monsoon Rainfall, ENSO and Equatorial Indian Ocean Oscillation. Geophysical Research Letters, 31, Article ID: L12213. https://doi.org/10.1029/2004GL019733

[74] You, Q., Kang, S., Pepin, N. and Yan, Y. (2008) Relationship between Trends in Temperature Extremes and Elevation in the Eastern and Central Tibetan Plateau, 1961-2005. Geophysical Research Letters, 35, Article ID: L04704. https://doi.org/10.1029/2007GL032669

[75] Kaspari, S., Mayewshi, P., Kang, S., Sneed, S., Hou, S., Hooke, R., Kreutz, K., Introne, D., Handley, M., Maasch, K., Qin, D. and Ren, J. (2007) Reduction in the Northward Incursions of the South Asian Monsoon Since 1400 AD Inferred from a Mt. Everest Ice Core. Geophysical Research Letters, 34, Article ID: L16701. https://doi.org/10.1029/2007GL030440

[76] Liou, K.N., Lee, W.-L. and Hall, A. (2007) Radiative Transfer in Mountains: Application to the Tibetan Plateau. Geophysical Research Letters, 34, Article ID: L23809. https://doi.org/10.1029/2007GL031762

[77] Tapponnier, P., Zhiqin, X., Roger, F., Meyer, B., Arnaud, N., Wittlinger, G. and Jingsui, Y. (2001) Oblique Stepwise Rise and Growth of the Tibet Plateau. Science, 294, 1671-1677. https://doi.org/10.1126/science.105978

[78] Harrison, T.M., Copeland, P., Kidd, W.S.F. and Yin, A. (1992) Rising Tibet. Science, 255, 1663-1670. https://doi.org/10.1126/science.255.5052.1663

[79] Xu C., Liu, J., Song, C., Jiang, W. and Shi, C. (2000) GPS Measurements of Present-Day Uplift in the Southern Tibet. Earth, Planets Space, 52, 735-739.

https://doi.org/10.1186/BF03352274

[80] Wang, C., Zhao, X., Liu, Z., Lippert, P.C., Graham, S.A., Coe, R.S., Yi, H., Zhu, L., Liu, S. and Li, Y. (2008) Constraints on the Early Uplift History of the Tibetan Plateau. Proceedings of the National Academy of Sciences of the United States of America, 105, 4987-4992. https://doi.org/10.1073/pnas.0703595105

[81] Meijer, P.T. and Wortel, M.J.R. (1992) The Dynamics of Motion of the South American Plate. Journal of Geophysical Research: Solid Earth, 97, 11915-11931. 
https://doi.org/10.1029/91JB01123

[82] Albert, J.S., Val, P. and Hoorn, C. (2018) The Changing Course of the Amazon River in the Neogene: Center Stage for Neotropical Diversification Neotropical Ichthyology. Neotropical Ichthyology, 16, Article ID: e180033.

https://doi.org/10.1590/1982-0224-20180033

[83] Web Reference (2012) Cross-Section of Amazon Basin and South American Plate (Image).

https://nephicode.blogspot.com/2012/09/three-very-important-questions-part-iv.ht $\underline{\mathrm{ml}}$

[84] Goulding, M., Barthem, R. B. and Duenas, R. (2003) The Smithsonian Atlas of the Amazon. Smithsonian Books, Washington DC.

[85] Feng, M., Lee, S. and Assumpção, M. (2007) Upper Mantle Structure of South America from Joint Inversion of Waveforms and Fundamental Mode Group Velocities of Rayleigh Waves. Journal of Geophysical Research, 112, Article ID: B04312. https://doi.org/10.1029/2006]B004449

[86] Braun, J. (2010) The Many Surface Expressions of Mantle Dynamics. Nature Geoscience, 3, 825-833. https://doi.org/10.1038/ngeo1020

[87] Adhikari, S. and Ivins, E.R. (2016) Climate-Driven Polar Motion: 2003-2015. Science Advances, 2, Article ID: e1501693. https://doi.org/10.1126/sciadv.1501693

[88] Lambert, S. and Sottili, G. (2019) Is There an Influence of the Pole Tide on Volcanism? Insights from Mount Etnarecent Activity. Geophysical Research Letters, 46, 13730-13736. https://doi.org/10.1029/2019GL085525

[89] Lemoine, F.G., Goossens, S., Sabaka, T.J., Nicholas, J.B., Mazarico, E., Rowlands, D.D., Loomis, B.D., Chinn, D.S., Caprette, D.S., Neumann, G.A., Smith, D.E. and Zuber, M.T. (2013) High-Degree Gravity Models from GRAIL Primary Mission Data. Journal of Geophysical Research: Planets, 118, 1676-1698.

https://doi.org/10.1002/jgre.20118 